\title{
M2-like macrophages and tumor-associated macrophages: overlapping and distinguishing properties en route to a safe therapeutic potential
}

Ofer Guttman* and Eli C. Lewis

Ben-Gurion University of the Negev, Faculty of Health Sciences, Department of Clinical Biochemistry \& Pharmacology, Israel

\begin{abstract}
Macrophages are innate leukocytes ubiquitously present in nearly all tissues, and hold critical importance for tissue homeostasis, initiation and progression of immunological responses and tissue regeneration after injury. Two of the hallmarks of macrophages are variability and plasticity. Macrophages may polarize into either pro- or anti-inflammatory phenotypes (M1-like and M2-like macrophages, respectively), and various stimuli may shift their polarization across this spectrum. Typically, M1-like macrophages are involved in the onset and progression of autoimmune disorders, while M2-like macrophages have been demonstrated to effectively ameliorate such disorders by inducing the resolution of inflammatory responses and driving cellular proliferation and tissue regeneration. Many of the properties of M2-like macrophages are also characteristic of tumor-associated macrophages (TAMs), which are monocyte-derived cells that are subverted by tumors into potent pro-tumor agents capable of dampening anti-tumor cytotoxicity and facilitating tumor proliferation, angiogenesis and metastatic spread. Use of M2-polarizing immunotherapy for treatment of autoimmune disorders is a novel concept that holds promise for resolution of such disorders. However, concerns may be raised regarding the safety of such approaches as they may create tumor-permissive conditions. Here, we review current knowledge regarding the role of macrophages in autoimmunity and tumor immunology, and discuss the potential benefits and caveats of M2-polarizing therapies.
\end{abstract}

\begin{abstract}
Abbreviations: T1D: Type 1 Diabetes, T2D: Type 2 Diabetes, IBD: Inflammatory Bowel Disease, MS: Multiple Sclerosis, TAM: TumorAssociated Macrophage, TGF $\beta$ : Tumor Growth Factor $\beta$, TNFa: Tumor Necrosis Factor $\alpha$, VEGF: Vascular Endothelial Growth Factor, EGF: Epidermal Growth Factor: bFGF: Basic Fibroblast Growth Factor

\section{Introduction}

Macrophages comprise one of the central pillars of the immune system. While they represent a major component of the innate immune system, macrophages are uniquely poised as regulators of interaction between non-immune tissues and nearly all leukocyte compartments, both innate and adaptive [1-3]. Furthermore, tissue macrophage is intimately associated with the differentiation of numerous immune and non-immune cell populations, and may take part in nearly all forms of wound healing and tissue regeneration upon encountering appropriate conditions [4]. Such functions are primarily carried out in a paracrine fashion, by secretion of a wide variety of growth factors and cytokines, as well as nitric oxide (NO) and reactive oxygen species (ROS).
\end{abstract}

One of the most intriguing aspects of macrophage biology is their high degree of heterogeneity and plasticity. This is evident by the multitude of macrophage-secreted factors $[5,6]$ and by the ability of the cells to attain a site- and context-specific phenotype [7]. Macrophages are a source of both pro- and anti-inflammatory factors and populations of pro- and anti-inflammatory macrophages may be found in close proximity [8]. In addition to their paracrine activities, macrophage act as professional antigen presenting cells (pAPCs); plasticity is seen in this regard as well, as various macrophage subsets may hold a distinct antigen-presenting capacity [6]. The versatility of the cells is intentional; a pro-inflammatory profile would serve to, e.g., readily decontaminate an infected tissue while promoting local injury and facilitating antigen-specific helper $\mathrm{T}$ cell localization. In contrast, an anti-inflammatory profile would most commonly promote tissue maintenance, wound resolution and tissue repair, a feat commonly exerted by resident tissue macrophages upon inflammatory resolution. While pro-inflammatory macrophages are often termed M1-like and anti-inflammatory macrophages are termed M2-like, polarization towards either M1 or M2 is not binary; M1 and M2 macrophages merely represent two extremes of a continuum of activation states.

The relationship between macrophages and tumor cells is intricate. Macrophages are capable of directly killing tumor cells by secretion of excessive levels of NO. Similarly, inflammatory macrophages are central in supporting cytotoxic $\mathrm{T}$ cell responses by presentation of tumor antigens to helper T cells and local secretion of Th1-supporting cytokines [4,6]. By encouraging helper $\mathrm{T}$ cells, the environment becomes well suited for cytotoxic $\mathrm{T}$ cells to undertake cytotoxic killing of tumor antigen-bearing tumor cells. However, one finds that tumors do contain macrophages, and that these tumor-associated macrophages (TAMs) are in fact central for tumor survival.

TAMs may dampen anti-tumor immune activity, as well as secrete

Correspondence to: Ofer Guttman, PhD, Department of Clinical Biochemistry \& Pharmacology, Faculty of Health Sciences, Ben-Gurion University of the Negev, 1 Rager st., Beer-Sheva 84101, Israel, Tel/Fax: ++972-6400830, E-mail: guttmano@post.bgu.ac.il

Key words: macrophage polarization, autoimmune disorder, autoimmune diabetes, inflammatory bowel disease, multiple sclerosis, immunotherapy, tumorassociated macrophages, tumor immunology

Received: August 01, 2016; Accepted: August 25, 2016; Published: August 29 , 2016 
tumor-promoting growth factors, drive angiogenesis and facilitate metastatic spread $[3,5,6,9-13]$. In a way, this renders TAMs somewhat similar to M2-like macrophages [5,6,9,14]. Most notably, they share the capacity to drive tissue remodeling and curb local deleterious immune reactions. Based on these virtues, clinical use of M2-polarizing therapies holds promise in the treatment of autoimmune and autoinflammatory disorders. However, concomitantly, concerns are raised as to potential pro-tumor effects inherent to such approaches. In the present review, we highlight differences and similarities between TAMs and M2-like macrophages in an attempt to optimize emerging novel therapeutic approaches for macrophage manipulation in immune disorders and in cancer.

\section{Origins of macrophage populations as foundation to a rich local assortment}

The process of macrophage development remains a matter of debate. According to an early model, all macrophages that are present in an adult animal originate from bone marrow hematopoietic progenitor cells [15]. Such progenitor cells were previously thought to mature in an orderly manner into blood-borne monocytes, then infiltrate tissues and subsequently differentiate into mature macrophages [16]. However, recent evidence is suggestive of tissue resident macrophages originating from embryonic cells. These include yolk sac-derived macrophages in the liver, skin, spleen, brain and lungs [17-19], as well as chimeric macrophages in lungs and kidneys that display evidence for both yolk sac and hematopoietic stem cell origins [17-19]. These findings hold far-reaching implications. As will be further discussed in this review, significant differences exist in the polarization and activation of local resident macrophages and macrophages derived from tissue-infiltrating monocyte. These differences are particularly evident in pathologies associated with loss of immunological homeostasis, such as occurs in autoimmune disorders or might be an outcome of tumor evasion of the immune system.

The recruitment of monocytes towards inflamed tissues involves both immune and non-immune cell populations. Distressed tissues, including tumors, induce the secretion of monocyte-recruiting chemokines such as RANTES (CCL5), SDF-1 (CXCL12) and fractalkine (CXC3L1) [20-22]. Growth factors may also contribute to monocyte attraction to the inflammatory tissue, such as transforming growth factor $\beta$ (TGF $\beta$ ), vascular endothelial growth factor (VEGF) and basic fibroblast growth factor (bFGF) [22-24]. The presence of a gradient of chemoattractants is critical for the expression of integrin molecules by endothelial cells adjacent to the inflammatory site; such integrins include VCAM-1, ICAM-1, E-selectin and p-selectin [25-27]. Sufficient expression of selectins on the surface of endothelial cells will promote binding, rolling and attachment of blood-borne leukocytes to the endothelial wall [28].

\section{M1/M2 macrophage polarization}

While monocyte recruitment is a major component in tissue inflammatory responses, the manner in which infiltrating monocytes thereafter polarize may critically skew subsequent occurrences. Being a highly versatile cell type, macrophages may polarize to different inflammatory profiles according to local conditions. While the M1/M2 nomenclature is widely used, this classification system represents the two extremes of observed macrophage profiles and does not exclude the presence of intermediary polarization states.

The M1-like pro-inflammatory polarization state is the result of activation by interferon $\gamma(\operatorname{IFN} \gamma)$ and LPS. M1-like macrophages are characterized by their inclination to secrete Th1-inducing cytokines, such as tumor necrosis factor $\alpha$ (TNF $\alpha)$, IL-12, IL-18 and IFNa/ $\beta$, possession of an advanced antigen-presenting capacity and a robust expression of inducible nitric oxide synthase (iNOS), accompanied by release of large amounts of local NO [11-13,29-31]. Indeed, M1-like macrophages are capable of directly killing tumor cells by secretion of NO $[32,33]$, as well as by presenting tumor antigens to $\mathrm{CD} 4^{+} \mathrm{Th} 1$ cells and driving the activity of cytotoxic $\mathrm{CD} 8^{+} \mathrm{T}$ cells at the tumor site [34,35]. Accordingly, M1-like macrophages have been shown to inhibit tumor development and progression in vivo [32,36-39]. Thus, the ability of M1-like macrophages to directly kill tumor cells as well as their intimate association with anti-tumor Th1 responses, suggests that manipulation of tumor-infiltrating macrophage may comprise a unique opportunity in boosting anti-tumor immunity.

M2-like macrophages are typically involved in removal of tissue debris, tissue remodeling and repair. They may also take part in initiation of allergic reactions. This polarization state includes a wide variety of possible phenotypes. Therefore, a classification system has been established that divides M2-like macrophages into several subclasses: M2a-like polarization is induced by stimulation with IL-4 and IL-13 and is associated with Th2-type allergic immune activation $[5,40]$. The M2b-like profile is observed in macrophages exposed to the combination of $\mathrm{IL}-1 \beta$ and immune complexes (i.e., soluble antigen-binding antibodies), and is considered an immunoregulatory phenotype. Interestingly, M2b-like macrophages are characterized by simultaneous secretion of anti-inflammatory agents (predominantly IL-10) and inflammatory cytokines, such as TNFa and IL-6 [5,11]. M2c-like polarization is brought about by high concentrations of local IL-10; these macrophages secrete high levels of TGF $\beta$, IL-10, various growth factors and interestingly, versican, an ECM proteoglycan that interacts with cells by binding to non-integrin and integrin receptors, and $\alpha 1$-antitrypsin, an immunomodulatory acute phase reactant that promotes wound healing $[3,5,11]$. These cells are considered antiinflammatory and are often associated with the phase of inflammatory resolution, concomitant with wound healing and tissue regeneration $[3,5,11]$.

The three subclasses of M2-like macrophages share certain properties, such as expression of IL-10, reduced expression of costimulatory molecules (such as CD80/86 and CD40) and limited antigen-presenting capacity [41]. However, it is apparent that they are differentiated by virtue of separate secretory profiles and by order of temporal appearance along the course of an inflammatory reaction [42]. Significantly, numerous other activation phenotypes have been described for macrophages beyond the three established M2like polarization states; it is increasingly apparent that macrophage polarization is variable in separate tissues and in the presence of distinct conditions.

\section{Macrophage polarization within tissues susceptible to autoimmunity}

For scope consideration, we will hereby explore the role of macrophages in autoimmune settings by collecting evidence from three autoimmune and autoinflammatory pathologies: type 1 diabetes (T1D), inflammatory bowel disease (IBD) and multiple sclerosis (MS).

\section{Macrophages are dangerous but essential inhabitants of the endocrine pancreatic islet}

While insulin-secreting $\beta$ cells comprise the majority of pancreatic 
islet cells, regulation of islet development, function and physiological glucose homeostasis is primarily steered by non- $\beta$ cells [43], including intra-islet resident macrophages. For example, an agitated macrophage might spread inflammatory signals in its immediate vicinity, effectively shutting down insulin release and promoting local insulin resistance, as exercised by, e.g., TNFa [44]. Intra-islet macrophages have been depicted throughout embryonic development and adult life [45]. In a study that examined mice with a mutation in the gene for granulocytemacrophage colony stimulating factor (GM-CSF) (op/op mice [46]) whereby the animals lack macrophages in pancreatic islets and most other peripheral tissues, animals display a significantly diminished $\beta$ cell mass [46]. Consistent with such an unexpected role for resident islet macrophages, Calderon et al. have established that steady state islet macrophages display M1-like pro-inflammatory polarization properties [44]. Interestingly, when macrophage depletion was followed by introduction of naïve bone marrow cells, donor-derived isletinfiltrating monocytes rapidly acquired this very same inflammatory polarization [44]. Both these studies depict a critical role for islet resident macrophages during steady state conditions.

Dysregulation of intra-islet immune cell compartments and the emergence of chronic inflammatory conditions within the islets are common characteristics of both T1D and T2D. Nonetheless, significant immunological differences separate the two syndromes: autoimmune T1D is categorically associated with the mounting of serum autoantibodies specific to $\beta$ cell antigens [47] and with autoreactive $\mathrm{CD} 8^{+}$cytotoxic $\mathrm{T}$ cell responses directed against $\beta$ cells $[48,49]$, two entities that are not included in the clinical definition of T2D. However, macrophages appear to be a critical component of both syndromes: M1-like polarization is intimately associated with promotion of peripheral insulin resistance, islet inflammation and loss of $\beta$ cell mass [50,51]. Accordingly, adoptive transfer of M2-like macrophages was found to prevent the onset of autoimmune diabetes in the NOD mouse model [52]. Similarly, in models of T2D, ablation [53] and depletion [54,55] of macrophages reduced $\beta$ cell loss and induced improved glucose reactivity.

The role of islet resident macrophages extends beyond the immunological context, as macrophages have been found to be indispensable for $\beta$ cell proliferation elicited by the $\beta$ cell-toxic agent, STZ, in vivo [56-58]. In a seminal study, the sustained induction of inflammatory conditions in the pancreas by partial bile duct ligation ( $\mathrm{pBDL}$ ) was shown to promote M2-like polarization of local macrophages and to facilitate macrophage-dependent $\beta$ cell proliferation through secretion of TGF $\beta$ and epidermal growth factor (EGF) [56]. This study effectively demonstrates that while depletion of M1-like pro-inflammatory macrophages may assist in reduction of short-term damage and loss of $\beta$ cell mass, it might not be an ideal approach to deplete islets from macrophages altogether; properly activated M2-like macrophages seem to be effective drivers of $\beta$ cell proliferation upon local injury, and may thus restore functional pancreatic islets to the diabetic patients.

\section{Gastrointestinal tract macrophages are posted at a chronically hostile border}

The gastrointestinal (GI) tract has a steady-state population of resident macrophages that may be divided into discrete populations of pro-inflammatory and anti-inflammatory (regulatory) macrophages [59]. The heterogeneity of GI tract macrophage populations is thought to provide a 'safety valve', ensuring that the status quo of a healthy tissue is maintained while an uninterrupted capacity to mount anti-bacterial activities is present on call [59]. It is perhaps for this reason that intestinal macrophages constitutively express the immunoregulatory cytokine, IL-10 [60,61], and do not readily respond to bacterial stimuli with pro-inflammatory cytokine production [62]. This form of immune tolerance may, however, shift rapidly during acute GI tract infection or mucosal degradation, during which an intense infiltrate of inflammatory macrophages is observed, along with significantly increased secretion of inflammatory cytokines, as well as NO and ROS [63-66]. It remains unclear whether the rapid appearance of inflammatory macrophages during acute GI tract infection is brought about by infiltration of inflammatory monocytes from the circulation, or rather by polarization of pre-existing resident macrophages.

Intended to readily eradicate invasive bacteria [62,67-69], the inflamed GI tract also plays a key role in the onset and progression of various forms of IBD. IBD is characterized by the presence of chronic inflammatory conditions in the GI tract, which lead to degeneration of mucosal barriers and the replacement of functional intestinal tissue with non-functional fibrous tissue. Innate leukocytes, and in particular macrophages, are thought to hold a central role in this pathology [70-72]. Treatment of severe combined immunodeficient (SCID) mice with dextran sodium sulfate (DSS) results in the onset of colitis [73], demonstrating the central role of innate leukocytes rather than adaptive leukocytes in IBD. Furthermore, while IL-10 KO animals develop colitis without the need for an exogenous trigger, such as DSS, depletion of phagosomes effectively ameliorates colitis [74], as does blockade of monocyte recruitment in a colitis model [75].

While these studies effectively demonstrate the importance of M1like pro-inflammatory macrophages for disease onset, it is important to note that M2-like macrophages have been shown to exercise protective properties in colitis models [76-78]. Studies employing adoptive transfer of M2-like polarized macrophages $[79,80]$, as well as M2polarizing agents $[81,82]$ or agents that inhibit M1-polarization [83] have revealed a capacity of M2-like macrophages to diminish IBD severity and to promote intestinal wound healing [84].

\section{Macrophages poised between injury and recovery in the central nervous system}

MS is thoroughly different from IBD. It involves sterile inflammation and is not characterized by the formation of fibrotic tissue, and furthermore involves the prototypical loss of myelin and degradation of axon functions in the central nervous system (CNS) [85]. While MS was long thought to be induced by the activity of autoreactive $\mathrm{T}$ cells, increasing appreciation is being afforded to the intricate role of macrophages in this pathology.

Unlike in the case of pancreatic islets or the GI tract, the CNS does not have a population of resident macrophages [86,87]. Rather, CNS-associated inflammation induces the recruitment of circulating monocytes which then differentiate into macrophages and act to remove cellular debris and to secrete cytokines and growth factors. The high degree of variability in macrophage functions in MS is well documented. Studies have demonstrated disease-facilitation by proinflammatory M1-like macrophages [88,89], and amelioration of symptoms by depletion of macrophages [90]. However, evidence also points to a clear tissue-regenerative role for macrophages present in the CNS [91]. Studies employing macrophage transplantation to a neuronal lesion site [86,92] demonstrated superior recovery from neuronal damage, while mice that lack the CCR2 chemokine receptor, involved in monocyte recruitment to neuronal injury sites, displayed 
accelerated loss of neuronal functions in a model of Alzheimer's disease $[93,94]$.

Experimental autoimmune encephalomyelitis (EAE) is a commonly-used animal model of MS, which is characterized by inflammation-induced neuronal degeneration of a relapsingremitting nature [85]. A pathological M1/M2 ratio in favor of M1-like macrophages has been shown to promote relapsing EAE while adoptive transfer of M2-like macrophages was shown to support remission and neuronal recovery [95].

\section{Macrophage polarization in tumors}

\section{Tumors benefit from promoting TAM polarization}

Inflammation has long been considered a prerequisite for tumor development, and monocyte-derived cells (including macrophages) predominate as the major leukocyte subtype found within the majority of tumors $[9,11,96]$. Yet the plasticity of macrophages allows them to readily polarize to either pro- or anti-inflammatory profiles. Thus, it is intriguing to find that the inflammatory axis in established tumors is typically accompanied by macrophages that display M2-like characteristics, such as poor antigen-presenting capabilities, as well as abundant release of IL-10, TGF $\beta$, VEGF and EGF, and low expression of IL-12 and IFN $\alpha / \beta[6,9,11,30]$. Much like one would find in resident macrophages scattered within steady-state tissues. Yet unlike tissueresident macrophages, TAMs are thought to originate in inflammatory monocytes that infiltrate tumor sites and subsequently undergo maturation to macrophages [97-99].

The precise factors that govern TAM differentiation have yet to be fully elucidated, as each tumor is characterized by unique physical conditions and cytokine milieu. However, certain common features may be suggested. Hypoxic conditions are a nearly universal feature of primary tumors, and hypoxia-induced stabilization of hypoxiainducible factor $1 \alpha$ (HIF1 $\alpha$ ) and HIF2 $\alpha$ in macrophages leads to expression of genes associated with M2-like polarization [100]. Indeed, HIF1 $\alpha$ and HIF2 $\alpha$ are commonly present in TAMs within various types of tumors. Interestingly, tumor cell-derived lactic acid was found to mediate HIFla-associated VEGF expression and the subsequent polarization of TAMs towards the M2-like phenotype [101]. Cytokines derived from both tumor cells and local non-monocyte immune compartments are also central in macrophage differentiation. IL-10 and TGF $\beta$ released from tumor cells and regulatory T cells (Tregs) are powerful drivers of TAM polarization [5,9], as is colony stimulating factor-1 (CSF-1) $[30,35]$. Blockade of the CSF-1 receptor attenuates tumor growth and enhances $\mathrm{CD}^{+} \mathrm{T}$ cell infiltration [102,103]. It appears that tumors utilize diverse mechanisms to dampen Th1-type cytotoxic responses, in part by diverting $\mathrm{T}$ cells towards a Th2-type response; Th 2 cells secrete large amounts of IL- 4 and IL- 13 that promote M2-like polarization of TAMs [9]. In support of this concept, studies have shown that in vivo treatment with IFN $\gamma$ [104] or augmentation of the NF- $\kappa B$ pathway [105] may reverse M2-like polarization of TAMs towards M1-like characteristics.

\section{TAMs can promote both tumor growth and tumor spread}

TAMs promote a tumor-favorable environment. These unique macrophages have been shown to exert broad activities such as dampening of anti-tumor cytotoxic responses, promotion of tumor cell proliferation and facilitation of angiogenesis, as well as recruitment of naïve blood-borne monocytes to the tumor site $[9,12,13,106,107]$. Yet, TAMs may incorporate elements characteristic of both M1-like and M2-like macrophages.
While expression of iNOS and secretion of NO is primarily a feature of M1-like macrophages, TAMs have been shown to express iNOS, albeit at a relatively low level [108]. While NO is toxic to tumor cells at excessive concentrations, low but persistent levels of NO may benefit tumor development by augmenting genetic instability, thus aiding tumor cells in overwhelming the meticulous regulation of cellular proliferation [109]. Expression of iNOS by TAMs may therefore be regarded as the subversion, or 'hijacking' of a classic M1like tool towards pro-tumor purposes.

Secretion of growth factors is among the most important tumorpromoting functions of TAMs. Growth factors commonly secreted by TAMs include VEGF, EGF, TGF $\beta$ and bFGF [110]. While growth factor secretion is an integral part of macrophage functions in wound healing, sustained exposure of tissues to growth factors may promote proliferation of tumor cells and tumor-associated cell populations $[11,30,107]$. Aside from VEGF, a TAM-derived angiogenesis factor with obvious implication on tumor progression, growth factors have been shown to induce the proliferation of epithelial cells bearing cancer-associated mutations [111]; TAM-derived TGF $\beta$ was shown to induce epithelial-to-mesenchymal transition (EMT) [112], as well as persistent activation of cancer-associated fibroblasts, which then promote tissue remodeling and drive tumor cell proliferation [113].

Metastatic spread is also affected by TAMs. A unique paracrine loop appears to form between TAMs and tumor cells in the migration process necessary for metastatic spread. Specifically, relocation of tumor cells from tissues towards blood vessels is dependent on EGF signaling and is blocked by inhibition of EGF receptor signaling [114]. The stimulation of TAMs and tumor cells with CSF-1 and EGF, respectively, induces a 'lock-step' migration process in which the two cellular populations promote migration through tissue regions rich in extracellular matrix (ECM] [115]. In parallel, paracrine co-stimulation of tumor cells and TAMs enhances ECM-remodeling capacities of both cellular types [116].

\section{TAMs are capable of suppressing anti-tumor immune responses}

TAMs have been shown to curb anti-cancer immune responses through a variety of mechanisms. These include secretion of soluble immunosuppressive agents, such as IL-10, TGF $\beta$ and IL-1 receptor antagonist (IL-1Ra) [6,12,117], as well as expression of contactdependent immunosuppressive receptors, such as PD-L1 [118] and B7-H4 [119]. TAMs utilize such mechanisms along with secretion of specific chemokines in order to dampen cytotoxic $\mathrm{CD}^{+} \mathrm{T}$ cell activity, as well as induce the differentiation of $\mathrm{CD}^{+} \mathrm{T}$ cells into IL-4-producing Th2 cells and drive the recruitment and differentiation of regulatory $\mathrm{T}$ cells [41]. Importantly, chemokines associated with the M1-like phenotype such as CXCL9 and CXCL10, or M2-like phenotypes such as CCL17 and CCL22 display reciprocal behavior: M2-inducing signals inhibit the expression of chemokines associated with M1-like activation, and vice-versa [41].

TAMs also exert metabolic control over leukocyte activation at the tumor site. A potent suppressor of adaptive $\mathrm{T}$ cell responses, the tryptophan-metabolizing enzyme indolamine 2,3-dioxygenase (IDO) is regularly expressed by TAMs [120]. Similarly, nicotinamide adenine dinucleotide (NAD), another end-product of tryptophan metabolism, is a regulator of IL-6 and TNFa in monocytes [121]. Iron metabolism is a major component of immunoregulation; M1-like macrophages express high levels of Ferritin and low levels of Ferroportin and CD163, in effect sequestering iron and limiting local bacterial growth [122]. In 
contrast, M2-like macrophages express high levels of Ferroportin and CD163 and low levels of Ferritin, and thereby deposit extracellular iron that drives immunoregulation, tissue re-modeling and cellular proliferation [122].

\section{Discussion}

The importance of M2-like macrophages in the regulation of immune and inflammatory responses is widely accepted, as is their potential to ameliorate a wide range of autoimmune disorders. Further necessitating an evaluation of the clinical use of M2-polarizing agents is the alarming rise in the incidence of autoimmune and autoinflammatory syndromes, such as T1D, T2D, the various forms of IBD and MS. Successful skewing of macrophages in the affected tissue from M1-like pro-inflammatory cells, known for their capacity to decontaminate tissues at the cost of widespread tissue injury, to M2-like tissue-protective cells, may not only halt the progression of autoimmune activation, but also effectively drive the regeneration of disrupted tissues. The capability of M2-like macrophages to induce the proliferation of islet $\beta$ cells [56] exemplifies the advantage of M2polarizing treatments over total macrophage depletion. However, M2like polarization does not represent a discreet activation state; several separate M2-like polarization profiles may be induced [5]. Therefore, clinical manipulation of macrophage polarization must explicitly consider local tissue conditions. In addition, the high degree of similarity between TAMs and M2-like macrophages, particularly M2c macrophages, raises a major point of contention. M2-like macrophage potently drive cellular proliferation and angiogenesis and in many cases exercise immunoregulation over innate and adaptive leukocyte compartments [5]; these properties are also found in TAM populations. To date, no studies have examined models suitable for the elucidation of such an important question. Furthermore, the polarization of macrophages to the M2-like profile does not in itself necessarily represent a tumor-conductive factor. While the polarization of TAMs is thought to be induced by factors secreted by tumor cells, TAMs in and of themselves do not necessarily induce the de novo emergence of tumor cells. It is presently unknown whether adoptive transfer of TAMs may promote tumor development. Yet, any potential use of sustained immunotherapy for treatment of autoimmune pathologies such as T1D or MS, must therefore be preceded by detailed examination of systemic influences and, in particular, address the possible reduction in immune surveillance. Also, sustained immunosuppression correlates with severely reduced wound healing and tissue regeneration and, in the case of T1D, most clinical approaches centered on immunosuppression have proven largely ineffective [123,124].

It is currently unknown whether TAMs, as potent effectors in the progression of tumors, may ameliorate autoimmune disorders. The adoptive transfer of purified TAMs from tumor-bearing animals for the treatment of autoimmune disorders in non-tumor-bearing animals is a novel concept that may offer great insights into the subtle differences between M2-like macrophages and TAMs. Yet when one considers the negative effects of immunosuppression over the benefit of tissue regeneration, it is evident that sustained treatment of autoimmune disorders with immunosuppressive regimens might preclude long-term healing and resolution. The potential use of immunotherapeutic agents aimed at reversing macrophage polarization in affected tissues is therefore an appealing possibility, with the potential for successfully resolving inflammatory conditions, curbing autoimmune responses and driving successful tissue regeneration towards regain of function. However, further studies are required in order to fully explore the immunological and physiological implications of the novel utilization of macrophage polarization strategies.

\section{References}

1. Biswas SK, Mantovani A(2010) Macrophage plasticity and interaction with lymphocyte subsets: cancer as a paradigm. Nat Immunol 11: 889-896. [Crossref]

2. Gordon S, Martinez FO (2010) Alternative activation of macrophages: mechanism and functions. Immunity 32: 593-604. [Crossref]

3. Martinez FO, Helming L, Gordon S (2009) Alternative activation of macrophages: an immunologic functional perspective. Annu Rev Immunol 27: 451-483. [Crossref]

4. Wynn TA, Chawla A, Pollard JW (2013) Macrophage biology in development, homeostasis and disease. Nature 496: 445-455. [Crossref]

5. Mantovani A, Sica A (2010) Macrophages, innate immunity and cancer: balance, tolerance, and diversity. Curr Opin Immunol 22: 231-237. [Crossref]

6. Mantovani A, Sozzani S, Locati M, Allavena P, \& Sica A (2002) Macrophage polarization: tumor-associated macrophages as a paradigm for polarized M2 mononuclear phagocytes. Trends in Immunology 23: 549-555.

7. Davies LC, Jenkins SJ, Allen JE, Taylor PR (2013) Tissue-resident macrophages. Nat Immunol 14: 986-995. [Crossref]

8. Daems WT, Poelman RE, Brederoo P, van Lohuzen EJ (1973) Peroxidatic activity in resident peritoneal macrophages and exudate monocytes of the guinea pig after ingestion of latex particles. J Histochem Cytochem 21: 93-95. [Crossref]

9. Mantovani A, Allavena P1 (2015) The interaction of anticancer therapies with tumorassociated macrophages. J Exp Med 212: 435-445. [Crossref]

10. Mantovani A, Bottazzi B, Colotta F, Sozzani S, Ruco L (1992) The origin and function of tumor-associated macrophages. Immunol Today 13: 265-270. [Crossref]

11. Mantovani A, et al. (2004) Infiltration of tumours by macrophages and dendritic cells: tumour-associated macrophages as a paradigm for polarized M2 mononuclear phagocytes. Novartis Found Symp 256: 137-145. [Crossref]

12. Sica A, Allavena P, Mantovani A (2008) Cancer related inflammation: the macrophage connection. Cancer Lett 267: 204-215. [Crossref]

13. Sica A, Larghi P, Mancino A, Rubino L, Porta C, et al. (2008) Macrophage polarization in tumour progression. Semin Cancer Biol 18: 349-355. [Crossref]

14. Balkwill F, Mantovani A (2001) Inflammation and cancer: back to Virchow? Lancet 357 539-545. [Crossref]

15. Gordon S, Taylor PR (2005) Monocyte and macrophage heterogeneity. Nat Rev Immunol 5: 953-964. [Crossref]

16. Geissmann F, Manz MG, Jung S, Sieweke MH, Merad M, et al. (2010) Development of monocytes, macrophages, and dendritic cells. Science 327: 656-661. [Crossref]

17. Ginhoux F, Greter M, Leboeuf M, Nandi S, See P, et al. (2010) Fate mapping analysis reveals that adult microglia derive from primitive macrophages. Science 330: 841-845. [Crossref]

18. Hoeffel G, Wang Y, Greter M, See P, Teo P, et al. (2012) Adult Langerhans cells derive predominantly from embryonic fetal liver monocytes with a minor contribution of yolk sac-derived macrophages. J Exp Med 209: 1167-1181. [Crossref]

19. Schulz C, Gomez Perdiguero E, Chorro L, Szabo-Rogers H, Cagnard N, et al. (2012) A lineage of myeloid cells independent of Myb and hematopoietic stem cells. Science 336: 86-90. [Crossref]

20. Bottazzi B, Polentarutti N, Acero R, Balsari A, Boraschi D, et al. (1983) Regulation of the macrophage content of neoplasms by chemoattractants. Science 220: 210-212. [Crossref]

21. Mantovani A, Allavena P, Sozzani S, Vecchi A, Locati M, et al. (2004) Chemokines in the recruitment and shaping of the leukocyte infiltrate of tumors. Semin Cancer Biol 14: 155-160. [Crossref]

22. Reed JR, Stone MD, Beadnell TC, Ryu Y, Griffin TJ, et al. (2012) Fibroblast growth factor receptor 1 activation in mammary tumor cells promotes macrophage recruitment in a CX3CL1-dependent manner. PloS one 7: e45877. [Crossref]

23. Bierie B, Moses HL (2010) Transforming growth factor beta (TGF-beta) and inflammation in cancer. Cytokine Growth Factor Rev 21: 49-59. [Crossref]

24. Linde N, Lederle W, Depner S, van Rooijen N, Gutschalk CM, et al. (2012) Vascular 
endothelial growth factor-induced skin carcinogenesis depends on recruitment and alternative activation of macrophages. J Pathol 227: 17-28. [Crossref]

25. Ivetic A (2013) Signals regulating L-selectin-dependent leucocyte adhesion and transmigration. Int J Biochem Cell Biol 45: 550-555. [Crossref]

26. Sperandio M (2006) Selectins and glycosyltransferases in leukocyte rolling in vivo. FEBS J 273: 4377-4389. [Crossref]

27. Zarbock A, Ley K, McEver RP, \& Hidalgo A (2011) Leukocyte ligands for endothelia selectins: specialized glycoconjugates that mediate rolling and signaling under flow. Blood 118: 6743-6751. [Crossref]

28. Sullivan DP, Muller WA (2014) Neutrophil and monocyte recruitment by PECAM CD99, and other molecules via the LBRC. Semin Immunopathol 36: 193-209. [Crossref]

29. Allavena P, Sica A, Garlanda C, Mantovani A (2008) The Yin-Yang of tumor-associated macrophages in neoplastic progression and immune surveillance. Immunol Rev 222: 155-161. [Crossref]

30. Allavena P, Sica A, Solinas G, Porta C, Mantovani A (2008) The inflammatory microenvironment in tumor progression: the role of tumor-associated macrophages. Crit Rev Oncol Hematol 66: 1-9. [Crossref]

31. Verreck FA, de Boer T, Langenberg DM, Hoeve MA, Kramer M, et al. (2004) Human IL-23-producing type 1 macrophages promote but IL-10-producing type 2 macrophages subvert immunity to (myco)bacteria. Proc Natl Acad Sci U S A 101: 45604565. [Crossref]

32. Sinha P, Clements VK, Ostrand-Rosenberg S (2005) Reduction of myeloid-derived suppressor cells and induction of M1 macrophages facilitate the rejection of established metastatic disease. J Immunol 174: 636-645. [Crossref]

33. Klimp AH, de Vries EG, Scherphof GL, Daemen T (2002) A potential role of macrophage activation in the treatment of cancer. Crit Rev Oncol Hematol 44: 143161. [Crossref]

34. Schreiber RD, Old LJ, Smyth MJ (2011) Cancer immunoediting: integrating immunity's roles in cancer suppression and promotion. Science 331: 1565-1570. [Crossref]

35. Sica A, Mantovani A (2012) Macrophage plasticity and polarization: in vivo veritas. $J$ Clin Invest 122: 787-795. [Crossref]

36. Heusinkveld M, de Vos van Steenwijk PJ, Goedemans R, Ramwadhdoebe TH, Gorter A, et al. (2011) M2 macrophages induced by prostaglandin E2 and IL-6 from cervical carcinoma are switched to activated M1 macrophages by CD4+ Th1 cells. $J$ Immunol 187: 1157-1165. [Crossref]

37. Klug F, Prakash H, Huber PE, Seibel T, Bender N, et al. (2013) Low-dose irradiation programs macrophage differentiation to an iNOS $(+) / \mathrm{M} 1$ phenotype that orchestrates effective T cell immunotherapy. Cancer cell 24: 589-602. [Crossref]

38. Ren F, Fan M, Mei J, Wu Y, Liu C, et al. (2014) Interferon-gamma and celecoxib inhibit lung-tumor growth through modulating M2/M1 macrophage ratio in the tumor microenvironment. Drug Des Devel Ther 8: 1527-1538. [Crossref]

39. Ma J, Liu L, Che G, Yu N, Dai F, et al. (2010) The M1 form of tumor-associated macrophages in non-small cell lung cancer is positively associated with survival time. BMC Cancer 10: 112. [Crossref]

40. Martinez FO, Sica A, Mantovani A, Locati M (2008) Macrophage activation and polarization. Front Biosci 13: 453-461. [Crossref]

41. Mantovani A, Sica A, Sozzani S, Allavena P, Vecchi A, et al. (2004) The chemokine system in diverse forms of macrophage activation and polarization. Trends Immunol 25: 677-686. [Crossref]

42. Gensel JC, Zhang B2 (2015) Macrophage activation and its role in repair and pathology after spinal cord injury. Brain Res 1619: 1-11. [Crossref]

43. Soria B, Andreu E, Berná G, Fuentes E, Gil A, et al. (2000) Engineering pancreatic islets. Pflugers Arch 440: 1-18. [Crossref]

44. Calderon B, Carrero JA, Ferris ST, Sojka DK, Moore L, et al. (2015) The pancreas anatomy conditions the origin and properties of resident macrophages. J Exp Med 212: 1497-1512. [Crossref]

45. Hume DA, Halpin D, Charlton H, Gordon S (1984) The mononuclear phagocyte system of the mouse defined by immunohistochemical localization of antigen F4/80: macrophages of endocrine organs. Proc Natl Acad Sci U S A 81: 4174-4177. [Crossref]

46. Banaei-Bouchareb L, Gouon-Evans V, Samara-Boustani D, Castellotti MC, Czernichow $\mathrm{P}$, et al. (2004) Insulin cell mass is altered in Csflop/Csflop macrophage-deficient mice. J Leukoc Biol 76: 359-367. [Crossref]
47. Atkinson MA, Eisenbarth GS, Michels AW (2014) Type 1 diabetes. Lancet 383: 69-82. [Crossref]

48. Chatenoud L, Thervet E, Primo J, Bach JF (1994) Anti-CD3 antibody induces longterm remission of overt autoimmunity in nonobese diabetic mice. Proc Natl Acad Sci US A 91: 123-127. [Crossref]

49. Phillips JM, et al. (2009) Type 1 diabetes development requires both CD4+ and CD8+ T cells and can be reversed by non-depleting antibodies targeting both $\mathrm{T}$ cell populations. Rev Diabet Stud 6: 97-103. [Crossref]

50. Nackiewicz D, Dan M, He W, Kim R, Salmi A, et al. (2014) TLR2/6 and TLR4activated macrophages contribute to islet inflammation and impair beta cell insulin gene expression via IL-1 and IL-6. Diabetologia 57: 1645-1654. [Crossref]

51. Ehses JA, Perren A, Eppler E, Ribaux P, Pospisilik JA, et al. (2007) Increased number of islet-associated macrophages in type 2 diabetes. Diabetes 56: 2356-2370. [Crossref]

52. Parsa R, Andresen P, Gillett A, Mia S, Zhang XM, et al. (2012) Adoptive transfer of immunomodulatory M2 macrophages prevents type 1 diabetes in NOD mice. Diabetes 61: 2881-2892. [Crossref]

53. Patsouris D, Li PP, Thapar D, Chapman J, Olefsky JM, et al. (2008) Ablation of CD11cpositive cells normalizes insulin sensitivity in obese insulin resistant animals. Cell Metab 8: 301-309. [Crossref]

54. Bu L, Gao M, Qu S, Liu D (2013) Intraperitoneal injection of clodronate liposomes eliminates visceral adipose macrophages and blocks high-fat diet-induced weight gain and development of insulin resistance. AAPS J 15: 1001-1011. [Crossref]

55. Feng B, Jiao P, Nie Y, Kim T, Jun D, et al. (2011) Clodronate liposomes improve metabolic profile and reduce visceral adipose macrophage content in diet-induced obese mice. PloS one 6: e24358. [Crossref]

56. Xiao X, Gaffar I, Guo P, Wiersch J, Fischbach S, et al. (2014) M2 macrophages promote beta-cell proliferation by up-regulation of SMAD7. Proc Natl Acad Sci U S A 111: E1211-1220. [Crossref]

57. Brissova M, Aamodt K, Brahmachary P, Prasad N, Hong JY, et al. (2014) Islet microenvironment, modulated by vascular endothelial growth factor-A signaling, promotes $\beta$ cell regeneration. Cell Metab 19: 498-511. [Crossref]

58. Cao X, Han ZB, Zhao H, Liu Q (2014) Transplantation of mesenchymal stem cells recruits trophic macrophages to induce pancreatic beta cell regeneration in diabetic mice. Int J Biochem Cell Biol 53: 372-379. [Crossref]

59. Mowat AM, Bain CC (2011) Mucosal macrophages in intestinal homeostasis and inflammation. J Innate Immun 3: 550-564. [Crossref]

60. Hadis U, Wahl B, Schulz O, Hardtke-Wolenski M, Schippers A, et al. (2011) Intestinal tolerance requires gut homing and expansion of FoxP3 + regulatory $\mathrm{T}$ cells in the lamina propria. Immunity 34: 237-246. [Crossref]

61. Kamada N, Hisamatsu T, Okamoto S, Sato T, Matsuoka K, et al. (2005) Abnormally differentiated subsets of intestinal macrophage play a key role in Th1-dominant chronic colitis through excess production of IL-12 and IL-23 in response to bacteria. Journal of Immunology 175: 6900-6908.

62. Smith PD, Smythies LE, Shen R, Greenwell-Wild T, Gliozzi M, et al. (2011) Intestinal macrophages and response to microbial encroachment. Mucosal Immunol 4: 31-42. [Crossref]

63. Hausmann M, Obermeier F, Schreiter K, Spottl T, Falk W, et al. (2004) Cathepsin D is up-regulated in inflammatory bowel disease macrophages. Clin Exp Immunol 136: 157-167. [Crossref]

64. Mahida YR, Wu KC, Jewell DP (1989) Respiratory burst activity of intestinal macrophages in normal and inflammatory bowel disease. Gut 30: 1362-1370. [Crossref]

65. Rogler G, Brand K, Vogl D, Page S, Hofmeister R, et al. (1998) Nuclear factor kappaB is activated in macrophages and epithelial cells of inflamed intestinal mucosa. Gastroenterology 115: 357-369. [Crossref]

66. Rugtveit J, Nilsen EM, Bakka A, Carlsen H, Brandtzaeg P, et al. (1997) Cytokine profiles differ in newly recruited and resident subsets of mucosal macrophages from inflammatory bowel disease. Gastroenterology 112: 1493-1505.

67. Dunay IR, Fuchs A, Sibley LD (2010) Inflammatory monocytes but not neutrophils are necessary to control infection with Toxoplasma gondii in mice. Infect Immun 78 : 1564-1570. [Crossref]

68. Rhee SJ, Walker WA, Cherayil BJ (2005) Developmentally regulated intestinal expression of IFN-gamma and its target genes and the age-specific response to enteric Salmonella infection. J Immunol 175: 1127-1136. [Crossref] 
69. Takeuchi D1, Jones VC, Kobayashi M, Suzuki F (2008) Cooperative role of macrophages and neutrophils in host Antiprotozoan resistance in mice acutely infected with Cryptosporidium parvum. Infect Immun 76: 3657-3663. [Crossref]

70. Lissner D, Schumann M, Batra A, Kredel LI, Kühl AA, et al. (2015) Monocyte and M1 Macrophage-induced Barrier Defect Contributes to Chronic Intestinal Inflammation in IBD. Inflamm Bowel Dis 21: 1297-1305. [Crossref]

71. Mahida YR (2000) The key role of macrophages in the immunopathogenesis of inflammatory bowel disease. Inflamm Bowel Dis 6: 21-33. [Crossref]

72. Steinbach EC, Plevy SE (2014) The role of macrophages and dendritic cells in the initiation of inflammation in IBD. Inflamm Bowel Dis 20: 166-175. [Crossref]

73. Dieleman LA, Ridwan BU, Tennyson GS, Beagley KW, Bucy RP, et al. (1994) Dextran sulfate sodium-induced colitis occurs in severe combined immunodeficient mice. Gastroenterology 107: 1643-1652. [Crossref]

74. Watanabe N, Ikuta K, Okazaki K, Nakase H, Tabata Y, et al. (2003) Elimination of loca macrophages in intestine prevents chronic colitis in interleukin-10-deficient mice. Dig Dis Sci 48: 408-414. [Crossref]

75. Kanai T, Uraushihara K, Totsuka T, Nemoto Y, Fujii R, et al. (2006) Ameliorating effect of saporin-conjugated anti-CD11b monoclonal antibody in a murine T-cell-mediated chronic colitis. J Gastroenterol Hepatol 21: 1136-1142. [Crossref]

76. Hunter MM, Wang A, Parhar KS, Johnston MJ, Van Rooijen N (2010) In vitroderived alternatively activated macrophages reduce colonic inflammation in mice. Gastroenterol 138: 1395-1405. [Crossref]

77. Weisser SB, Brugger HK, Voglmaier NS, McLarren KW, van Rooijen N, et al. (2011) SHIP-deficient, alternatively activated macrophages protect mice during DSS-induced colitis. Journal of Leukocyte Biology 90: 483-492. [Crossref]

78. Weisser SB, et al. (2014) Arginase activity in alternatively activated macrophages protects PI3Kp110delta deficient mice from dextran sodium sulfate induced intestinal inflammation. European J Immunol 44: 3353-3367. [Crossref]

79. Haribhai D, Ziegelbauer J, Jia S, Upchurch K, Yan K, et al. (2016) Alternatively Activated Macrophages Boost Induced Regulatory T and Th17 Cell Responses during Immunotherapy for Colitis. J Immunol 196: 3305-3317. [Crossref]

80. Cosín-Roger J, Ortiz-Masiá D, Calatayud S, Hernández C, Esplugues JV, et al. (2016) The activation of Wnt signaling by a STAT6-dependent macrophage phenotype promotes mucosal repair in murine IBD. Mucosal Immunol 9: 986-998. [Crossref]

81. Jang SE, Hyam SR, Han MJ, Kim SY, Lee BG, et al. (2013) Lactobacillus brevis G-101 ameliorates colitis in mice by inhibiting NF-1 ${ }^{\circ} \mathrm{B}$, MAPK and AKT pathways and by polarizing M1 macrophages to M2-like macrophages. J Appl Microbiol 115: 888-896. [Crossref]

82. Paynich ML, Jones SE, \& Knight KL (2016) Commensal exopolysaccharides induce M2 macrophages that prevent pathogen-induced colitis. The Journal of Immunology 196(1 Supplement):131.133.

83. Lin Y, Yang X, Yue W, Xu X, Li B, et al. (2014) Chemerin aggravates DSS-induced colitis by suppressing M2 macrophage polarization. Cell Mol Immunol 11: 355-366. [Crossref]

84. Seno H, Miyoshi H, Brown SL, Geske MJ, Colonna M, et al. (2009) Efficient colonic mucosal wound repair requires Trem2 signaling. Proc Natl Acad Sci U S A 106: 256261. [Crossref]

85. Liu C1, Li Y, Yu J, Feng L, Hou S, et al. (2013) Targeting the shift from M1 to M2 macrophages in experimental autoimmune encephalomyelitis mice treated with fasudil. PLoS One 8: e54841. [Crossref]

86. Lazarov-Spiegler O, Solomon AS, Zeev-Brann AB, Hirschberg DL, Lavie V, et al. (1996) Transplantation of activated macrophages overcomes central nervous system regrowth failure. FASEB $J$ 10: 1296-1302. [Crossref]

87. Perry VH1, Andersson PB, Gordon S (1993) Macrophages and inflammation in the central nervous system. Trends Neurosci 16: 268-273. [Crossref]

88. Hendriks JJ, Teunissen CE, de Vries HE, Dijkstra CD (2005) Macrophages and neurodegeneration. Brain Res Brain Res Rev 48: 185-195. [Crossref]

89. Kigerl KA, Gensel JC, Ankeny DP, Alexander JK, Donnelly DJ, et al. (2009) Identification of two distinct macrophage subsets with divergent effects causing either neurotoxicity or regeneration in the injured mouse spinal cord. J Neurosci 29: 1343513444. [Crossref]

90. Popovich PG, Guan Z, Wei P, Huitinga I, van Rooijen N, et al. (1999) Depletion of hematogenous macrophages promotes partial hindlimb recovery and neuroanatomical repair after experimental spinal cord injury. Exp Neurol 158: 351-365. [Crossref]
91. Miron VE, Boyd A, Zhao JW, Yuen TJ, Ruckh JM, et al. (2013) M2 microglia and macrophages drive oligodendrocyte differentiation during CNS remyelination. Nat Neurosci 16: 1211-1218. [Crossref]

92. Rapalino O, Lazarov-Spiegler O, Agranov E, Velan GJ, Yoles E, et al. (1998) Implantation of stimulated homologous macrophages results in partial recovery of paraplegic rats. Nat Med 4: 814-821. [Crossref]

93. El Khoury J, Toft M, Hickman SE, Means TK, Terada K, et al. (2007) Ccr2 deficiency impairs microglial accumulation and accelerates progression of Alzheimer-like disease. Nat Med 13: 432-438. [Crossref]

94. Naert G, Rivest S (2011) CC chemokine receptor 2 deficiency aggravates cognitive impairments and amyloid pathology in a transgenic mouse model of Alzheimer's disease. J Neurosci 31: 6208-6220. [Crossref]

95. Mikita J, Dubourdieu-Cassagno N, Deloire MS, Vekris A, Biran M, et al. (2011) Altered M1/M2 activation patterns of monocytes in severe relapsing experimental rat model of multiple sclerosis. Amelioration of clinical status by M2 activated monocyte administration. Mult Scler 17: 2-15. [Crossref]

96. Coussens LM, Werb Z (2002) Inflammation and cancer. Nature 420: 860-867. [Crossref]

97. Noy R, Pollard JW (2014) Tumor-associated macrophages: from mechanisms to therapy. Immunity 41: 49-61. [Crossref]

98. Franklin RA, Liao W, Sarkar A, Kim MV, Bivona MR, et al. (2014) The cellular and molecular origin of tumor-associated macrophages. Science 344: 921-925. [Crossref]

99. Shand FH, Ueha S, Otsuji M, Koid SS, Shichino S, et al. (2014) Tracking of intertissue migration reveals the origins of tumor-infiltrating monocytes. Proc Natl Acad Sci US A 111: 7771-7776. [Crossref]

100. Dehne N, Brüne B (2009) HIF-1 in the inflammatory microenvironment. Exp Cell Res 315: 1791-1797. [Crossref]

101. Colegio OR, Chu NQ, Szabo AL, Chu T, Rhebergen AM, et al. (2014) Functiona polarization of tumour-associated macrophages by tumour-derived lactic acid. Nature 513: 559-563. [Crossref]

102. Strachan DC, Ruffell B, Oei Y, Bissell MJ, Coussens LM, et al. (2013) CSF1R inhibition delays cervical and mammary tumor growth in murine models by attenuating the turnover of tumor-associated macrophages and enhancing infiltration by CD8 T cells. Oncoimmunology 2: e26968. [Crossref]

103. Ries CH, Cannarile MA, Hoves S, Benz J, Wartha K, et al. (2014) Targeting tumorassociated macrophages with anti-CSF-1R antibody reveals a strategy for cancer therapy. Cancer Cell 25: 846-859. [Crossref]

104. Duluc D, Corvaisier M, Blanchard S, Catala L, Descamps P, et al. (2009) Interferongamma reverses the immunosuppressive and protumoral properties and prevents the generation of human tumor-associated macrophages. Int J Cancer 125: 367-373. [Crossref]

105. Fong CH, Bebien M, Didierlaurent A, Nebauer R, Hussell T, et al. (2008) An antiinflammatory role for IKKbeta through the inhibition of "classical" macrophage activation. J Exp Med 205: 1269-1276. [Crossref]

106. Hanahan D, Weinberg RA (2011) Hallmarks of cancer: the next generation. Cell 144 646-674. [Crossref]

107. Balkwill F, Charles KA, Mantovani A (2005) Smoldering and polarized inflammation in the initiation and promotion of malignant disease. Cancer Cell 7: 211-217. [Crossref]

108. Klimp AH, Hollema H, Kempinga C, van der Zee AG, de Vries EG, et al. (2001) Expression of cyclooxygenase-2 and inducible nitric oxide synthase in human ovarian tumors and tumor-associated macrophages. Cancer Res 61: 7305-7309. [Crossref]

109. Wink DA, Vodovotz Y, Laval J, Laval F, Dewhirst MW, et al. (1998) The multifaceted roles of nitric oxide in cancer. Carcinogenesis 19: 711-721. [Crossref]

110. Mantovani A (2014) Macrophages, neutrophils, and cancer: A double edged sword. New Journal of Science.

111. Grivennikov SI, Greten FR, Karin M (2010) Immunity, inflammation, and cancer. Cell 140: 883-899. [Crossref]

112. Fan QM, Jing YY, Yu GF, Kou XR, Ye F, et al. (2014) Tumor-associated macrophages promote cancer stem cell-like properties via transforming growth factor-beta1induced epithelial-mesenchymal transition in hepatocellular carcinoma. Cancer Lett 352: 160-168. [Crossref]

113. Kunz-Schughart LA, Knuechel R (2002) Tumor-associated fibroblasts (part II) Functional impact on tumor tissue. Histol Histopathol 17: 623-637. [Crossref] 
114. Wyckoff J, Wang W, Lin EY, Wang Y, Pixley F, et al. (2004) A paracrine loop between tumor cells and macrophages is required for tumor cell migration in mammary tumors. Cancer Res 64: 7022-7029. [Crossref]

115. Condeelis J, Singer RH, Segall JE (2005) The great escape: when cancer cells hijack the genes for chemotaxis and motility. Annu Rev Cell Dev Biol 21: 695-718. [Crossref]

116. Yamaguchi H, Pixley F, Condeelis J (2006) Invadopodia and podosomes in tumor invasion. Eur J Cell Biol 85: 213-218. [Crossref]

117. Solinas G, Germano G, Mantovani A, Allavena P (2009) Tumor-associated macrophages (TAM) as major players of the cancer-related inflammation. J Leukoc Biol 86: 1065-1073. [Crossref]

118. Bloch O, Crane CA, Kaur R, Safaee M, Rutkowski MJ, et al. (2013) Gliomas promote immunosuppression through induction of $\mathrm{B} 7-\mathrm{H} 1$ expression in tumor-associated macrophages. Clin Cancer Res 19: 3165-3175. [Crossref]

119. Kryczek I, Zou L, Rodriguez P, Zhu G, Wei S, et al. (2006) B7-H4 expression identifies a novel suppressive macrophage population in human ovarian carcinoma. $J$ Exp Med 203: 871-881. [Crossref]

120. Grohmann U, Fallarino F, Puccetti P (2003) Tolerance, DCs and tryptophan: much ado about IDO. Trends Immunol 24: 242-248. [Crossref]

121. Van Gool F, et al. (2009) Intracellular NAD levels regulate tumor necrosis factor protein synthesis in a sirtuin-dependent manner. Nat Med 15: 206-210. [Crossref]

122. Cairo G, Recalcati S, Mantovani A, Locati M (2011) Iron trafficking and metabolism in macrophages: contribution to the polarized phenotype. Trends Immunol 32: 241 247. [Crossref]

123. Kaufman A, Herold KC (2009) Anti-CD3 mAbs for treatment of type 1 diabetes. Diabetes Metab Res Rev 25: 302-306. [Crossref]

124. Ludvigsson J, Faresjö M, Hjorth M, Axelsson S, Chéramy M, et al. (2008) GAD treatment and insulin secretion in recent-onset type 1 diabetes. $N$ Engl J Med 359: 1909-1920. [Crossref]

Copyright: $(02016$ Sharma P. This is an open-access article distributed under the terms of the Creative Commons Attribution License, which permits unrestricted use, distribution, and reproduction in any medium, provided the original author and source are credited. 